\title{
Review
}

\section{Exercise as a Time-conditioning Effector in Chronic Disease: a Complementary Treatment Strategy}

\author{
Luis F. B. P. Costa Rosa \\ Laboratory of Metabolism, Department of Histology and Embryology, Institute of Biomedical Sciences, University of \\ São Paulo, Brazil
}

\begin{abstract}
Exercise has been widely believed to be a preventive and therapeutic aid in the treatment of various pathophysiological conditions such as cardiovascular disease and cancer. A common problem associated with such pathologies is cachexia, characterized by progressive weight loss and depletion of lean and fat body mass, and is linked to poor prognosis. As this syndrome comprises changes in many physiological systems, it is tempting to assume that the modulation of the psychoneuroimmunoendocrine axis could attenuate or even prevent cachexia progression in cancer patients. Cancer cachexia is characterized by a disruption in the rhythmic secretion of melatonin, an important time-conditioning effector. This hormone, secreted by the pineal gland, transmits circadian and seasonal information to all organs and cells of the body, synchronizing the organism with the photoperiod. Considering that exercise modulates the immune response through at least two different mechanisms-metabolic and neuroendocrine-we propose that the adoption of a regular exercise program as a complementary strategy in the treatment of cancer patients, with the exercise bouts regularly performed at the same time of the day, will ameliorate cachexia symptoms and increase survival and quality of life.
\end{abstract}

Keywords: exercise - time-conditioning effector - neuroimmunoendocrine system - glutamine cachexia

\section{Introduction}

In many chronic diseases, such as cancer and chronic heart failure, patients die as a direct consequence of cachexia, a profound metabolic process characterized by the breakdown of skeletal muscle and deleterious, chaotic abnormalities in fat and carbohydrate metabolism (1). This syndrome is accompanied by changes in the neuroimmunoendocrine axis, as reviewed by Langstein and Norton (2) and Langhans (3). Physical exercise is one of the strategies adopted to counteract protein wasting during chronic diseases (4). In addition to the positive impact of exercise on protein metabolism, we propose that exercise acts as a 'time-conditioning effector' which regulates the neuroimmunoendocrine axis, increases survival and improves quality of life.

Exercise or regular physical activity has been widely adopted as a preventive or therapeutic aid in the treatment of numerous physiopathological conditions, including cardiovascular diseases (5) and some aspects of senescence (6). The

For reprints and all correspondence: Luis F.B.P. Costa Rosa, Lab. De Metabolismo, Instituto de Ciencias Biomedicas, Av. Prof. Lineu Prestes

1524, sala 302, Cidade Universitária, São Paulo 05508-900, Brazil.

E-mail: ggrosa@icb.usp.br immense potential of exercise in various conditions seems to be correlated to the fact that it promotes adaptations in all the systems of the organism. This concept about the beneficial effects of exercise on human health is quite recent. In the past, physicians traditionally advised patients with chronic diseases, such as cardiovascular disorders, to avoid physical activity. However, the investigation of cardiac rehabilitation in the 1960s showed the benefits of early mobilization after myocardial infarction, which led to the development of cardiac rehabilitation programs based on exercise (7-9). In fact, these studies served as a starting point for research on the effects of exercise on other systems and pathophysiological processes such as immune response, cancer and inflammation.

As evidence supporting cardiac rehabilitation programs is available, we have started developing a scientific basis for the use of exercise as an adjuvant therapy for cancer patients. In fact, exercise has been used to improve shoulder mobility after breast cancer surgery (10), to help maintain the energy balance during adjuvant chemotherapy $(4,11)$ and to improve the quality of life of cancer survivors $(12,13)$. Leung et al. (14) showed that serum obtained from patients who had undergone exercise programs had reduced $\mathrm{LNCaP}$ prostate 
cancer cell growth by $27 \%$, through an increase in cellular p53 protein content. Despite these emerging results, the present exercise programs are neither well defined nor included in the list of possible interventions for management of cancer symptoms.

\section{Exercise and the Immune System}

During the last two decades, a great effort has been made to understand the mechanisms that underlie the relationship between exercise and the immune system, as a second step in the study of the effects of physical activity on health. In fact, physical fatigue, caused by exercise or manual work, has long been considered a factor affecting susceptibility to illness. A study carried out in the earlier part of the previous century linked physical fatigue with increased susceptibility to poliomyelitis (15). Several studies provide epidemiological evidence that supports the anecdotal belief that regular exercise increases resistance to infections such as common cold whereas intense training is associated with increased upper respiratory tract infections (16-18). The positive effect of exercise on other diseases has also been acknowledged, and there is increasing evidence that physical activity, as a lifestyle, offers protection against malignancy (19).

This dual effect of exercise on the immune system led a group of scientists (20) to postulate a $J$-shaped curve to better express this relationship. Their results indicate that moderate intensity exercise lowers the incidence of infections while intense exercise increases it. Therefore, the present study aids to investigate the underlying mechanisms of such a relationship. Two principal research approaches have emerged in trying to establish a link between exercise and the immune system-a metabolic approach that involves glutamine metabolism (21), and another that considers changes in the neuroendocrine milieu as the mechanism for immunomodulation (22).

\section{Glutamine Hypothesis}

Glutamine is a 'conditionally essential' amino acid, which comprises $20 \%$ of the total plasma amino acids, and is actively produced in different organs-liver, kidneys, lungs and skeletal muscle (23) - under different pathophysiological conditions. Skeletal muscle is a major glutamine producer, and can release the amino acid into the bloodstream at a high rate $(24,25)$. During the 1980s, Professor Eric Newsholme, at the University of Oxford, demonstrated that rapidly dividing cells, such as lymphocytes, as well as macrophages, both immune cells possessing a high secretory activity, utilize high rates of glutamine even when quiescent (26-28). It was also demonstrated that the glutamine pathway in both cell types is under external regulation, partly because of the supply of glutamine itself $(26,27,29)$. Glutamine, when supplied to the immune cells in the proper concentration $(30,31)$, allows lymphocytes to proliferate, killer cells to respond to lymphokines, and immune cells to produce cytokines. It also reg- ulates macrophage function. The demand of the skeletal muscle and other organs for glutamine during intense exhaustive exercise, or after surgery, trauma, burns and sepsis, is such that the immune system may be forced into a glutamine debt, which temporarily affects its function (3234).

Poortmans et al. (35) and Decombaz et al. (36) reported that a biphasic response of plasma glutamine concentration is present during exercise. A short-term exercise results in an increase in plasma glutamine concentration $(27,35,37)$, while its concentration may decrease by as much as $25 \%$, after a full marathon (21). Rennie et al. (38) demonstrated that athletes who ran on a treadmill at $50 \%$ of the maximal oxygen uptake showed increased glutaminemia during the first three hours of running, followed by a $17 \%$ decrease below pre-exercise levels after $3.75 \mathrm{~h}$. This reduction in plasma glutamine concentration was also observed in overtrained athletes, who showed an unexplained decreased performance associated with higher incidence of upper respiratory tract infections $(39,40)$.

Castell et al., who studied more than 350 runners, reported that plasma glutamine concentration also falls after a marathon. They observed a $15 \%$ decrease in the amino acid concentration, $15 \mathrm{~min}$ after the end of the race, and an additional $15 \%$ decrease within the next hours, from 669 to $533 \mu \mathrm{mol} / \mathrm{l}(21)$. The magnitude and the duration of lowered plasma glutamine vary considerably with the type of sport studied and the intensity of the exercise bout. Walsh et al. (41) observed a reduction in plasma amino acid concentration $5 \mathrm{~h}$ after an exhaustive cycling protocol while Rhodes et $a l$. recorded the same observation in triathletes, $2 \mathrm{~h}$ after prolonged exercise. In our laboratory we found a reduction of $25 \%$ in plasma glutamine concentration after an Olympic triathlon, in well-trained, top-ranking athletes (42). A similar change was observed in athletes after 12 bouts of a 20 -min cycling protocol (20-min rest period between two bouts) at $95 \%$ of the maximum oxygen uptake (43). It is interesting to note that the group that received carbohydrate supplementation, in the latter experiment, did not show any change in plasma glutamine concentration (43). The same observation was recorded by Lehman et al. (44) and Castell (29) after ultramarathons, during which the runners stopped routinely for $15 \mathrm{~min}$ and ingested food and drinks ad libitum.

The decrease observed in glutaminemia correlates with increased symptoms of upper respiratory tract infections $(21,42)$, suggesting that immunodepression may occur in some athletes due to stress induced by prolonged, exhaustive exercise and competition. Some of the factors that might render athletes more vulnerable to opportunistic viruses or bacterial agents, as proposed by Castell (21), are a higher training mileage, additional stress (the mental stress of competition more than doubled the risk of getting an upper respiratory tract infection), a low body mass, bypassing the nasal filter mechanism (during exercise, athletes breathe through the mouth rather than through the nose, impairing the pro- 
tective effects of mucosal secretions) and a decrease in environmental temperature.

\section{Immune Changes after Exercise}

The most common changes in immune cell function after strenuous exercise comprise decreased neutrophil activity, impaired antibody synthesis, decreased immunoglobulin levels in blood and saliva, decreased cytolytic activity of natural killer (NK) cells, lower circulating T lymphocyte number for $3-4 \mathrm{~h}$ after exercise, a reduction in the proliferative ability of lymphocytes in response to mitogens, and profound changes in the profile of cytokines produced after exercise, including a 100 -fold increase in interleukin-6 production, and an augmented production of anti-inflammatory mediators $(21,22)$.

These changes are transient, and most of them return to the basal level a few hours after exercise. In general, however, there are some long-term changes in the immune response of athletes. The adaptive immune system (resting state) seems to be largely unaffected by intensive and prolonged exercise training $(45,46)$. The innate immune system appears to respond differently to the chronic stress of intensive exercise, with NK cell activity tending to be enhanced while neutrophil function is suppressed (47-50). However, the clinical significance of such changes remains to be elucidated.

\section{How to Deal with Changes in Plasma Glutamine?}

While considering the glutamine hypothesis, it is quite tempting to speculate that maintaining the plasma glutamine concentration within the normal range (found at rest) will restore the immune changes observed after strenuous exercise. Castell et al. $(51,52)$ supplemented athletes with 7 or $5 \mathrm{~g}$ of glutamine per day and found only a slight and transient increase in plasma amino acid levels, which was, nevertheless, enough to decrease the incidence of upper respiratory tract infections (URTI) (53) as well as to prevent the changes in the CD4 : CD8 ratio found in the athletes of the placebo group (52). Our own studies (42) showed a similar magnitude of decrease in the incidence of infections in triathletes, in a group of athletes supplemented for 1 month with branched chain amino acids-precursors for glutamine synthesis. The supplementation protocol was efficient in maintaining the plasma glutamine levels after an Olympic triathlon within the same range as that found at rest. The maintenance of plasma glutamine levels was paralleled by an augmented production of IL-1, IL-2, tumor necrosis factor $\alpha$ (TNF- $\alpha$ ), and interferon $\gamma($ IFN- $\gamma)$, with changes in the balance between Th1: Th2 type immune response. Another study on athletes reported a reduction in IL-4 production in the supplemented group after a $30-\mathrm{km}$ run (54), reinforcing the potential change in the type of immune response presented by the athletes who received branched chain amino acids as precursors for glutamine synthesis, and its diversion towards a Th1 type response, which promotes cellular immunity (55).
Therefore, it may be possible that the supplementation of glutamine or branched chain amino acids to athletes engaged in long-distance high-intensity exhaustive exercise might increase glutamine availability for the immune system at a critical period when athletes are vulnerable to opportunistic infections. On the other hand, moderate intensity exercise will warrant constant plasma glutamine concentration, which could be beneficial to the integrity of the immune response during wasting conditions such as cancer cachexia.

\section{The 'Open Window' Hypothesis}

The second hypothesis that attempts to explain the relationship between exercise and the immune system is based on the changes observed in the neuroendocrine system, and is known as the 'open window' hypothesis (22). During exercise, there is a marked increase in the plasma levels of adrenaline, noradrenaline, growth hormone and cortisol. Depending on the exercise intensity and duration, the profile of secretion of these hormones and their clearance rates are substantially modified $(22,56)$. Adrenaline, and to a lesser degree noradrenaline, seem to be responsible for the acute effects of exercise on lymphocyte dynamics and lymphocyte function (57) and NK cell activity (22). Increase in growth hormone and catecholamine levels mediates the acute effects on neutrophils whereas cortisol exerts its effects within a time lag of at least $2 \mathrm{~h}$, depending on the exercise duration and intensity, and therefore may help to maintain lymphopenia and neutrocytosis only after long-term exercise $(18,58)$. The role of $\beta$-endorphins is less clear, but possibly linked to the immediate recruitment of NK cells in the blood (22).

As shown by several authors $(43,54,59)$, exhaustive exercise induces a drift towards a Th1 type immune response associated with the production of glucocorticoids. Considering that glucocorticoids suppress the production of TNF- $\alpha$, IFN- $\gamma$ and IL-2 $(60,61)$, which are important regulators of the Th1 type immune response, and that humoral immunity decreases during exhaustion, we can accept this as an important mechanism to explain exercise-induced immunodepression. Another interesting aspect is the effect of catecholamines in shifting the immune response towards a Th2-mediated humoral immunity. This effect could counteract the immunodepression related to exhaustion immediately after an acute bout of exercise, thereby maintaining the homeostasis of the immune response in such conditions. In fact, this could be linked to the 'stress-immune paradox' (62). Dhabbar et al. observed an enhancement in delayed type hypersensitivity response after acute stress. However, their studies demonstrated that the immune response should be enhanced, and not depressed, to protect the host during acute physical and/or psychological stress (62-64). If the physical exercise or psychological stress is above the adaptive capacity of the organism, over a long period of time, the effect will be deleterious $(62,65)$.

The 'stress-immune paradox' could be correlated with the 'Cognitive Activation Theory of Stress', postulated by 


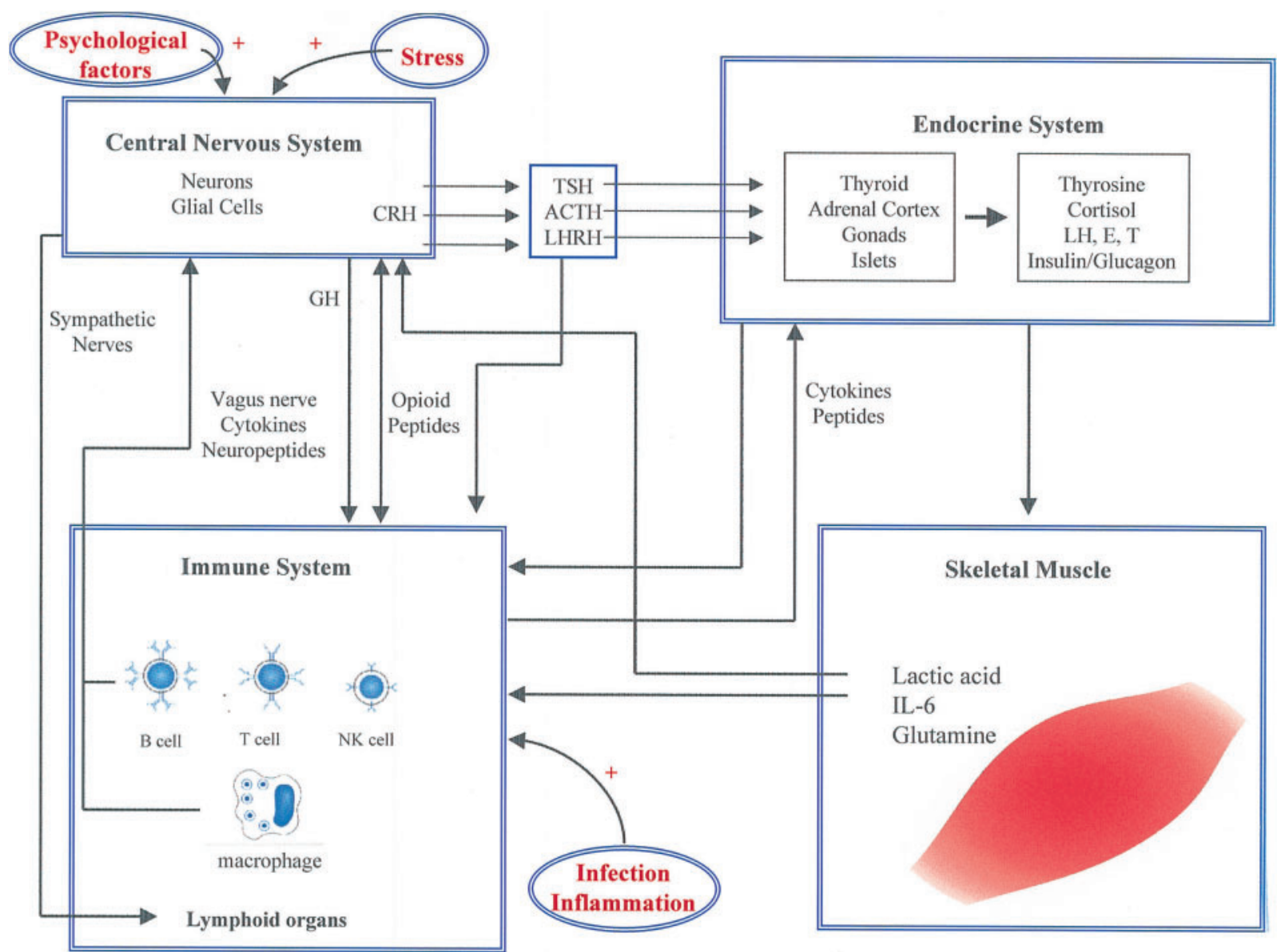

Figure 1. Interconnections among the nervous, immune, endocrine and muscular systems. These interactions involve the actions of small molecules such as neuropeptides and cytokines, hormone secretion, nervous activation and opioid peptides. ACTH, adrenocorticotropin hormone; $\mathrm{CRH}$, corticotropin releasing hormone; E, estrogen; T, testosterone; TSH, thyroid-stimulating hormone; GH, growth hormone; IL-6, interleukin 6; LH, luteinizing hormone; LHRH, luteinizing hormone-releasing hormone.

Eriksen et al. (66) as a reformulation of the stress theory, within a homeostatic and physiological framework. According to this theory, the phases of the response are interpreted as an alarm occurring within a complex cognitive network, with feedback and control loops. One important consequence of this approach, at least for the model that correlates immunological changes and exercise through a neuroendocrine mechanism, is that the response is dynamic and develops over time. This time element must be taken into account as the stress response develops in phases. A better understanding of these phases is crucial to predict the pathophysiological consequences of the relationships between the stressor and the observed physiological response. As postulated by Eriksen et al. (66), subjects with efficient coping show the fast- and short-lasting catecholamines response while subjects with high defense mechanisms (related to stimulus expectancies) may show more signs of prolonged activation. Non-coping individuals show a sustained general activation, which may develop into somatic disease or illness.

Therefore, many metabolic and hormonal changes observed during cachexia could be counteracted by those induced by regular exercise, known to promote changes that can be sustained for more than $24 \mathrm{~h}$ in the hormonal profile of athletes and also to positively modulate the immune response.

\section{Integrating the Systems: a Psychoneuroimmunoendocrine System}

Based on previous studies (67-70), we can hypothesize the existence of a neuroimmunoendocrine system that communicates through peptides, monoamines, glucocorticoids, free radicals, cytokines and opioids. Furthermore, neuropeptides found in the central nervous system, which show several immunomodulatory properties, are also expressed by immune cells $(71,72)$. Another interesting point that reinforces the existence of such an integrative axis is the presence of 'receptors' of various neurohormones and hypothalamic releasing factors in leukocytes $(67,68,70,73,74)$. Many authors, on the other hand, have postulated the existence of a psychoneuroimmunologic axis that $(69,75)$ integrates the central nervous system, behavior and the immune system. As the nervous and the immune system actively interact with the endocrine system, we can acknowledge a psychoneuro- 


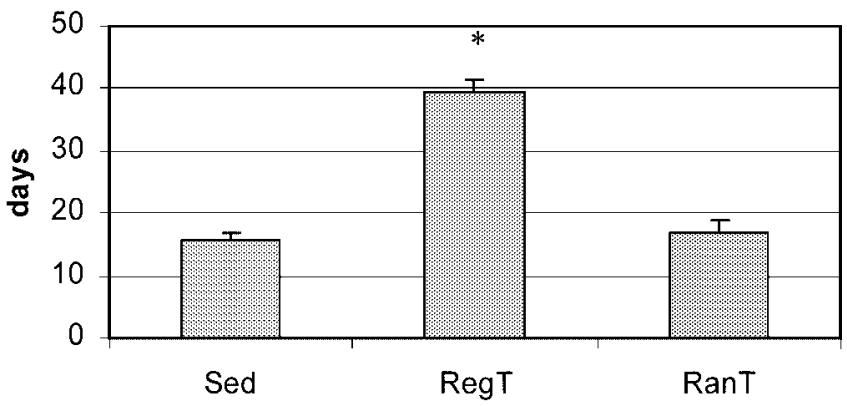

Figure 2. Life span of Walker-256 tumor-bearing rats trained for 8 weeks, 5 days a week, $3 \mathrm{~h}$ after the beginning of the dark period, at $60 \%$ maximum oxygen consumption (RegT), and that of tumor-bearing rats that followed the same training protocol, but exercised randomly throughout the day (RanT), compared with that showed by sedentary tumor-bearing animals (Sed). There were 25 animals/group, and the protocol described by Bacurau et al. (107) was followed. $* P<0.05$ for comparison with Sed group.

immunoendocrine system. This system is the key to understanding various mechanisms, which are still primarily a patchwork of loosely linked observations, and thereby provide novel but fundamentally unsubstantiated treatments for disorders such as cancer, as proposed by Schleifer (75).

In the early 1980 s, traditional immunologists and other scientists and physicians reviewed the proposal of this integrative system as an attempt to legitimize alternative medicine, and maintained that there was no correlation between psychosocial factors and survival in cancer patients $(76,77)$. However, over the last decade, evidence showing that psychological stress modulates the immune system has been accumulated. In fact, it seems that chronic stress, such as marital problems, work-related stress or bereavement, has a suppressive effect on the parameters of immune response (69), including a reduction in the number of $\mathrm{T}$ and $\mathrm{B}$ lymphocytes, decreased proliferative response to mitogens and decreased NK activity, leading to increased susceptibility to infections and worsening of existing diseases such as cancer. On the other hand, it seems that acute stress, such as examination stress or experimentally induced stress, has a positive impact on immune parameters $(69,78-82)$.

Considering the information presented in the previous paragraph, it seems quite impossible to avoid changing the terms 'chronic stress' and 'acute stress' to 'chronic exhaustive exercise' and 'acute exercise'. The assumption that exercise may be acting on a psychoneuroimmunoendocrine system opens multiple possibilities of using exercise as a therapy: preventing and/or reducing the incidence of chronic diseases, acting as a coadjuvant in the treatment of Alzheimer's disease (83), sub-acute low back pain (84), rheumatoid arthritis (85), fibromyalgia syndrome (86), cancer (87), chronic heart failure (88) and HIV-associated depression (89), among others.

Therefore, considering that an organism functions in an integrative manner, we can accept the proposal made by Professor Newsholme and integrate the skeletal muscle in our psychoneuroimmunoendocrine axis (Fig. 1) because glutamine seems to be essential for immune cells and its synthesis is controlled by hormones (90). In fact, when investigating the relationship between glutamine and the immune system during exercise, we tested the immune response of athletes subjected to 12 bouts of indoor cycling, 20 min each, with 20 min interval, at $95 \%$ of the maximal oxygen consumption. We observed that the athletes who received carbohydrate supplementation during the trial showed a blunted response of cortisol during exercise and were able to maintain plasma glutamine levels within the normal range (43). After exercise, the proliferative response of lymphocytes to mitogens as well as the production of IL-1, IL-2, IL-4 and TNF- $\alpha$ were restored to the pre-exercise levels, indicating that both hypothesesglutamine and 'open window' - cannot be excluded.

\section{Exercise as a 'Zeitgeber'}

In the past few years, the studies carried out in our laboratory provided evidence that led us to evaluate the possible effect of exercise as a 'Zeitgeber' or a time-conditioning effector. In mammals, the pineal gland transduces photoperiodic information to the neuroendocrine axis through nocturnal melatonin secretion (91). This hormonal message plays a key role in the biorhythm regulation, acting as a 'Zeitgeber', adjusting the internal clock to a 24-h cycle based on dark and light periods (91,92). Cachexia is a metabolic syndrome that occurs in about $80 \%$ of all advanced cancer patients and is associated with a decreased survival time $(93,94)$. It is defined as 'a wasting syndrome involving loss of muscle and fat directly caused by tumor factors or indirectly caused by an aberrant host response to tumor presence', characterized by breakdown of skeletal muscle and harmful, chaotic abnormalities in fat and carbohydrate metabolism, despite adequate nutritional intake $(1,95,96)$. These changes in energy metabolism are mediated by factors such as cytokines, serotonin, lactate, ketone bodies, glucocorticoids and thyroid hormones $(97,98)$. The net metabolic result is increased basal energy expenditure that reflects a global change in energy use, associated with wasting of energy reserves combined with anorexia, which significantly reduces caloric intake (99). Considering that melatonin transmits circadian and seasonal information to all organs and cells of the body, thereby synchronizing the physiological processes and metabolism including energy metabolism (100) with the daily and annual photoperiod variations, it seems quite reasonable to assume that changes in its profile would lead to a loss of metabolic control that facilitates the initiation of cachexia-related changes. In fact, Bartsch et al. (101) showed a tumor-dependent depression of serum melatonin in patients with prostate or breast cancer. However, according to Bartsch and Bartsch (102) it is unclear whether the plasma melatonin depletion in cancer patients is due to peripheral metabolic processes or a reduced production by the pineal gland. Therefore, considering the possible link between melatonin and cancer cachexia, we showed that the administration of a daily dose of melatonin to Walker-256 tumor-bearing rats extended the life span of the animals by approximately $100 \%$ (103). This 
result indicates that the rhythm of melatonin or its production may be impaired in our model, as previously described for other types of cancer $(101,104)$.

To better understand what happens to melatonin rhythm during cachexia, we determined the 24-h profile of melatonin production in tumor-bearing rats during cachexia development. Ferreira et al. (105) showed that during Walker-256 tumor progression, the animals showed profound changes in the profile of melatonin secretion, with changes in the secretory profile of the amine as well as in the total amount of its secretion and in the response of the pineal gland to noradrenaline stimulation. It is interesting to note that the total amount of melatonin produced increased during cancer cachexia, but the profile of production during the dark period was profoundly changed. In fact, we observed a dramatic alteration on day 7 after tumor implantation, when the first signs of cachexia could be observed in the tumor-bearing rats (106). We also detected the highest melatonin production on day 7 . On the day 14 , the melatonin secretory profile was different from that observed in control rats, but the total amount of melatonin secreted during the night decreased. The change in the total amount and in the profile of melatonin production by the pineal gland of tumor-bearing rats could be involved in cancer cachexia progression, leading to a disruption in metabolism.

We also demonstrated that a regular exercise program prolongs the life span of Walker-256 tumor-bearing rats (107). The animals were trained for $1 \mathrm{~h}$ every day, starting always at the same hour during the dark period. Interestingly, we found that the moderate intensity protocol $(60 \%$ maximal oxygen uptake) and the high-intensity protocol (85\% maximal oxygen uptake) provoked the same effect, increasing the rats' life span if the training sessions were carried out at the same hour during the day. If the daily exercise bout was performed randomly through the day, the increase in life span was abolished (Fig. 2). Therefore, it seems quite reasonable to assume that a possible mechanism to explain the effects of exercise upon cancer cachexia could be related to its ability to act as a 'time-conditioning effector', assuming the previous function of melatonin. In fact, Baehr et al. (108) showed that exercise can phase-shift the circadian rhythms of young adults if performed at the right time of the day. The literature provides evidence of many other time markers that may partially replace melatonin in entraining the organism, such as foodanticipatory activity (109), exogenous corticosteroids (110) or even a carbohydrate-rich meal (111). On the other hand, a loss in melatonin secretory pattern is observed during ageing (112) and some pathologies such as chronic fatigue syndrome (113), in which the prescription of a regular training program restores the sleep pattern and general feeling of wellness $(6,113)$. The potential role of exercise as a time-conditioning effector in different pathophysiological conditions needs to be further evaluated. The fact that a regular exercise program could postpone cell death by cancer cachexia assumes even more importance if we consider the premise of Zajicek (114) that the treatment of cancer patients is based on the false premise that the tumor is the only threat to the patient. Thus, exercise would be an important complementary and alternative strategy for the treatment of cachexia.

Therefore, taking into account that physical exercise affects all tissues and systems in the human body, interacting and modulating the psychoneuroimmunoendocrine system, that changes in the equilibrium of such a system during chronic diseases such as cancer and chronic heart failure lead to cachexia, and that during cachexia there is a loss of control of the internal rhythm through rhythmic melatonin production by the pineal gland, it seems that a regular exercise program could be a useful and low-cost intervention to reduce cachexia-related mortality as well as serving as a complementary strategy for improving the quality of life of cancer survivors and reducing costs of the public health system.

\section{References}

1. MacDonald N, Easson AM, Mazurak VC, Dunn G.P, Baracos VE. Understanding and managing cancer cachexia. J Am Coll Surg 2003; 197:143-61.

2. Langstein HN, Norton JA. Mechanisms of cancer cachexia. Hematol Oncol Clin North Am 1991;5:103-23.

3. Langhans W. Peripheral mechanisms involved with catabolism. Curr Opin Clin Nutr Metab Care 2002;5:419-26.

4. Zinna EM, Yarasheski KE. Exercise treatment to counteract protein wasting of chronic diseases. Curr Opin Clin Nutr Metab Care 2003;6: 87-93

5. Fang J, Wylie-Rosett J, Cohen HW, Kaplan RC, Alderman MH. Exercise, body mass index, caloric intake, and cardiovascular mortality. Am J Prev Med 2003;25:283-9.

6. Conn VS, Minor MA, Burks KJ, Rantz MJ, Pomeroy SH. Integrative review of physical activity intervention research with aging adults. $J \mathrm{Am}$ Geriatr Soc 2003;51:1159-68.

7. Dimeo F. Effects of exercise on cancer-related fatigue. Cancer 2001;92: 1689-93.

8. Velasco Rami JA, Maroto Montero JM. Cardiac rehabilitation: its historical evolution and current situation. Rev Esp Cardiol 1995;48:85-9.

9. Lucia A, Earnest C, Perez M. Cancer-related fatigue: can exercise physiology assist oncologists? Lancet Oncol 2003;1:616-25.

10. Bendz I, Olsen MF. Evaluation of immediate versus delayed shoulder exercises after breast cancer surgery including lymph node dissectionA randomized controlled trial. Breast 2002;11:241-8.

11. Harvie MN, Campbell IT, Baildam A, Howell A. Energy balance in early breast cancer patients receiving adjuvant chemotherapy. Breast Cancer Res Treat 2004;83:201-10.

12. Schneider CM, Dennehy CA, Roozeboom M, Carter SD. A model program: exercise intervention for cancer rehabilitation. Integr Cancer Ther 2002;1:76-82.

13. Courneya KS, Friedenreich CM, Quinney HA, Fields AL, Jones LW, Fairey AS. A randomized trial of exercise and quality of life in colorectal cancer survivors. Eur J Cancer Care (Engl) 2003;12:347-57.

14. Leung PS, Aronson WJ, Ngo TH, Golding LA, Barnard RJ. Exercise alters the IGF axis in vivo and increases p53 protein in prostate tumor cells in vitro. J Appl Physiol 2004;96:450-4.

15. Mackinonn LT. Exercise and resistance to infectious illness. In: Advances in Exercise Immunology, Human Kinetics, USA : Champaign: 1999,1-26.

16. Fitzgerald L. Exercise and the immune system. Immunol Today 1988;9: 337-9.

17. Nieman DC. Exercise end resistance to infection. Can J Physiol Pharmacol 1998;76:573-80.

18. Nieman DC, Pedersen BK. Exercise and immune function. Recent developments. Sports Med 1999;27:73-80.

19. Hoffman-Goetz L, Husted J. Exercise and cancer: do the biology and epidemiology correspond? Exerc Immunol Rev 1995;1:81-96.

20. Nieman DC. Is infection risk linked to exercise workload? Med Sci Sports Exerc 2000;32:S406-11. 
21. Castell L. Glutamine supplementation in vitro and in vivo, in exercise and immunodepression. Sports Med 2003;33:323-45.

22. Pedersen BK, Toft AD. Effects of exercise on lymphocytes and cytokines. Br J Sports Med 2000;34:246-51.

23. Newsholme EA, Calder PC. The proposed role of glutamine in some cells of the immune system and speculative consequences for the whole animal. Nutrition 1997;13:728-30.

24. Newsholme EA. Biochemical control logic and the metabolism of glutamine. Nutrition 1994;10:178-9.

25. Newsholme EA. The possible role of glutamine in some cells of the immune system and the possible consequence for the whole animal. Experientia 1996;52:455-9.

26. Ardawi MS, Newsholme EA. Intracellular localization and properties of phosphate-dependent glutaminase in rat mesenteric lymph nodes. Biochem J 1984;217:289-96.

27. Parry-Billings M, Baigrie RJ, Lamont PM, Morris PJ, Newsholme EA. Effects of major and minor surgery on plasma glutamine and cytokine levels. Arch Surg 1992;127:1237-40.

28. Newsholme P, Costa Rosa LFBP, Newsholme EA, Curi R. The importance of fuel metabolism to macrophage function. Cell Biochem Funct 1996;14:1-10

29. Castell LM. The Role Of Some Amino Acids in Exercise, Fatigue and Immunodepression. Oxford: University of Oxford, 1996.

30. Rohde T, Ullum H, Rasmussen JP, Kristensen JH, Newsholme E, Pedersen BK. Effects of glutamine on the immune system: influence of muscular exercise and HIV infection. J Appl Physiol 1995;79:146-50.

31. Rohde T, MacLean DA, Pedersen BK. Glutamine, lymphocyte proliferation and cytokine production. Scand J Immunol 1996;44:648-50.

32. Parry-Billings M, Leighton B, Dimitriadis G, de Vasconcelos PR, Newsholme EA. Skeletal muscle glutamine metabolism during sepsis in the rat. Int J Biochem 1989;21:419-23.

33. Parry-Billings M, Evans J, Calder PC, Newsholme EA. Does glutamine contribute to immunosuppression after major burns? Lancet 1990;336: 523-5.

34. Parry-Billings M, Budgett R, Koutedakis Y, Blomstrand E, Brooks S, Williams C, et al. Plasma amino acid concentrations in the overtraining syndrome: possible effects on the immune system. Med Sci Sports Exerc 1992;24:1353-8.

35. Poortmans JR, Siest G, Galteau MM, Houot O. Distribution of plasma amino acids in humans during submaximal prolonged exercise. Eur $J$ Appl Physiol Occup Physiol 1974;32:143-7.

36. Decombaz J, Reinhardt P, Anantharaman K, von Glutz G, Poortmans JR. Biochemical changes in a $100 \mathrm{~km}$ run: free amino acids, urea and creatinine. Eur J Appl Physiol Occup Physiol 1979;41:61-72.

37. Maughan RJ, Gleeson M. Influence of a $36 \mathrm{~h}$ fast followed by refeeding with glucose, glycerol or placebo on metabolism and performance during prolonged exercise. Eur J Appl Physiol Occup Physiol 1988;57: 570-6.

38. Rennie MJ, Edwards RH, Krywawych S, Davies CT, Halliday D, Waterlow JC, et al. Effect of exercise on protein turnover in man. Clin Sci (Lond) 1981;61:627-39.

39. Matthews DE, Campbell RG. The effect of dietary protein intake on glutamine and glutamate nitrogen metabolism in humans. Am J Clin Nutr 1992;55:963-70.

40. Rowbottom DG, Keast D, Morton AR. The emerging role of glutamine as an indicator of exercise stress and overtraining. Sports Med 1996;21: 80-97.

41. Walsh NP, Blannin AK, Clark AM, Cook L, Robson PJ, Gleeson M. The effects of high-intensity intermittent exercise on the plasma concentrations of glutamine and organic acids. Eur J Appl Physiol Occup Physiol 1998;77:434-8.

42. Bassit RA, Sawada LA, Bacurau RF, Navarro F, Costa Rosa LFBP. The effect of BCAA supplementation upon the immune response of triathletes. Med Sci Sports Med 2000;32:1214-9.

43. Bacurau RFP, Bassit RA, Sawada L, Navarro F, Martins E Jr, Costa Rosa LFBP. Carbohydrate supplementation during intense exercise and the immune response of cyclists. Clin Nutr 2002;21:423-9.

44. Lehmann M, Huonker M, Dimeo F, Heinz N, Gastmann U, Treis N, et al. Serum amino acids in nine athletes before and after the 1993 Colmar ultra triathlon. Int J Sports Med 1995;16:155-9.

45. Baj Z, Kantorski J, Majewska E, Zeman K, Pokoca L, Fornalczyk E, et al. Immunological status of competitive cyclists before and after a training season. Int J Sports Med 1994;15:319-24.
46. Nieman DC, Buckley KS, Henson DA, Warren BJ, Suttles J, Ahle JC, et al. Immune function in marathon runners versus sedentary controls. Med Sci Sports Exerc 1995;27:986-92.

47. Pedersen BK, Tvede N, Christensen LD, Klarlund K, Kragbak S, HalkjrKristensen J. Natural killer cell activity in peripheral blood of highly trained and untrained persons. Int J Sports Med 1989;10:129-31.

48. Nieman DC, Henson DA, Gusewitch G, Warren BJ, Dotson RC, Butterworth DE, et al. Physical activity and immune function in elderly women. Med Sci Spots Exerc 1993;25:823-31.

49. Hack V, Strobel G, Weiss M, Weicker H. PMN cell counts and phagocytic activity of highly trained athletes depend on training period. $J$ Appl Physiol 1994;77:1731-5.

50. Pyne DB, Baker MS, Fricker PA, McDonald WA, Telford RD, Weidemann MJ. Effects of an intensive 12-wk training program by elite swimmers on neutrophil oxidative activity. Med Sci Sports Exerc 1995; 27:536-42.

51. Castell LM, Liu CT, Newsholme EA. Diurnal variation of plasma glutamine in normal and fasting humans. Proc Nutr Soc 1995;54:118 A.

52. Castell LM, Newsholme EA. The effects of oral glutamine supplementation upon athletes after prolonged, exhaustive exercise. Nutrition 1997; 13:738-42.

53. Castell LM, Poortmans J, Newsholme EA. Does glutamine have a role in reducing infections in athletes? Eur J Appl Physiol Occup Physiol 1996;73: 488-91.

54. Bassit RA, Sawada LA, Bacurau RF, Navarro F, Martins E Jr, Santos $\mathrm{RV}$, et al. Branched-chain amino acid supplementation and the immune response of long distance athletes. Nutrition 2002;18:376-9.

55. Elenkov IJ, Chrousos G.P. Stress hormones, proinflammatory and antiinflammatory cytokines, and autoimmunity. Ann NY Acad Sci 2002; 966:290-303.

56. Sheppard RJ. Physical activity, training and the immune response. Carmel: Cooper Publishing Group: 1997.

57. Seelaender MC, Kazantzis M, Costa Rosa LFBP. The effect of adrenaline and Walker-256 tumour-induced cachexia upon Kupffer cell metabolism. Cell Biochem Funct 1999;17:151-6.

58. Pedersen BK, Bruunsgaard H, Klokker M, Kappel M, MacLean DA, Nielsen HB, et al. Exercise-induced immunomodulation: possible roles of neuroendocrine factors and metabolic factors. Int J Sports Med 1997;18: S2-7.

59. Lakier Smith L. Overtraining, excessive exercise, and altered immunity: is this a T helper-1 versus T helper-2 lymphocyte response? Sports Med 2003;33:347-64.

60. Beutler B, Krochin N, Milsark IW, Luedke C, Cerami A. Control of cachectin (tumor necrosis factor) synthesis: mechanisms of endotoxin resistance. Science 1986;232:977-80.

61. Boumpas DT, Chrousos GP, Wilder RL, Cupps TR, Balow JE. Glucocorticoid therapy for immune-mediated diseases: basic and clinical correlates. Ann Intern Med 1993;119:1198-208.

62. Dhabbar FS, McEwen BS. Acute stress enhances while chronic stress suppresses cell-mediated immunity in vivo: a potential role for leukocyte trafficking. Brain Behav Immun 1997;11:286-306.

63. Dhabbar FS, McEwen BS. Stress-induced enhancement of antigenspecific cell-mediated immunity. J Immunol 1996;156:2608-15.

64. Dhabbar FS. Acute stress enhances while chronic stress suppresses skin immunity. The role of stress hormones and leukocyte trafficking. Ann NY Acad Sci 2000;917:876-93.

65. Cohen S, Tyrrell DA, Smith AP. Psychological stress and susceptibility to the common cold. N Engl J Med 1991;325:606-12.

66. Eriksen HR, Olff M, Murison R, Ursin H. The time dimension in stress responses: relevance for survival and health. Psych Res 1999;85:39-50.

67. Blalock JE, Smith EM. A complete regulatory loop between the immune and neuroendocrine systems. Fed Proc 1985;44:108-11.

68. Weigent DA, Blalock JE. Production of peptide hormones and neurotransmitters by the immune system. Chem Immunol 1997;69:1-30.

69. Olff M. Stress, depression and immunity: the role of defense and coping styles. Psych Res 1999;85:7-15.

70. Salzet M, Vieau D, Day R. Crosstalk between nervous and immune systems through the animal kingdom: focus on opioids. TINS 2000;23: $550-5$.

71. Merrill JE, Benveniste EN. Cytokines in inflammatory brain lesions: helpful and harmful. Trends Neurosci 1996;19:331-8.

72. Martins E Jr, Ferreira ACF, Skorupa AL, Afeche SC, Cipolla-Neto J, Costa Rosa LFBP. Tryptophan consumption and indoleamines production by peritoneal cavity macrophages. J Leukoc Biol 2004. (in press) 
73. Carr DJ, DeCosta BR, Kim CH, Jacobson AE, Guarcello V, Rice KC, et al. Opioid receptors on cells of the immune system: evidence for deltaand kappa-classe. J Endocrinol 1989;122:161-8.

74. Bergeron F, Leduc R, Day R. Subtilase-like pro-protein convertases: from molecular specificity to therapeutic applications. $J$ Mol Endocrinol 2000;24:1-14.

75. Schleifer SJ. Psychoneuroimmunology: introductory comments on its physics and metaphysics. Psych Res 1999;85:3-6.

76. Maddox J. Psychoimmunology before its time. Nature 1984;309:400.

77. Angel M. Disease as a reflection of the psyche. NEngl J Med 1985;312: $1570-2$.

78. Brosschot JF, Smelt D, De Smet MBM, Heijnen CJ, Olff M, Baillieux RE, et al. Effects of experimental psychological stress on T-lymphocytes and NK-cells in man: an exploratory study. J Psychophysics 1991;5:5967.

79. Brosschot JF, Benschop RJ, Godaert GLR, De Smet MBM, Olff M, Heijnen CJ, et al. Effects of experimental psychological stress on distribution and function of peripheral blood cells. Psychosomatic Med 1992;54:394-406.

80. Brosschot JF, Benschop RJ, Godaert G.LR, Olff M, De Smet MBM, Heijnen $\mathrm{CJ}$ et al. Influence of life stress on immunological reactivity to mild psychological stress. Psychosomatic Med 1994;56:216-24.

81. Benschop RJ, Brosschot JF, Godaert GLR, De Smet MBM, Geenen R, Olff $\mathrm{M}$, et al. Chronic stress affects immunologic but not cardiovascular responsiveness to acute physiological stress in humans. Psych Med 1994;23:R75-80.

82. Benschop RJ, Godaert GLR, Geenen R, Brosschot JF, De Smet MBM, Olff M, et al. Relationships between cardiovascular and immunological changes in an experimental stress model. Psych Med 1995;25:323-7.

83. Teri L, Gibbons LE, McCurry SM, Logsdon RG, Buchner DM, Barlow WE, et al. Exercise plus behavioral management in patients with Alzheimer's disease: a randomized controlled trial. JAMA 2003;290:2015-22.

84. Storheim K, Brox JI, Holm I, Koller AK, Bo K. Intensive group training versus cognitive intervention in sub-acute low back pain: short-term results of a single-blind randomized controlled trial. J Rehabil Med 2003;35:132-40.

85. Pool AJ, Axford JS. The effects of exercise on the hormonal and immune systems in rheumatoid arthritis. Rheumatol 2001;40:610-4.

86. Altan L, Bingol U, Aykac M, Koc Z, Yurtkuran M. Investigation of the effects of pool-based exercise on fibromyalgia syndrome. Rheumatol Int 2003;24:341-6.

87. Carter SD, Drum SN, Hayward R, Schneider CM. A case study: prescriptive exercise intervention after bilateral mastectomies. Integr Cancer Ther 2003;2:34-8.

88. Witham MD, Struthers AD, McMurdo ME. Exercise training as a therapy for chronic heart failure: can older people benefit? J Am Geriatr Soc 2003;51:699-709.

89. Neidig JL, Smith BA, Brashers DE. Aerobic exercise training for depressive symptom management in adults living with HIV infection. $J$ Assoc Nurses AIDS Care 2003;14:30-40.

90. Mezzarobba VV, Torrent A, Leydier II, Alles S, Brajon B, Mignon M, et al. The role of adrenal hormones in the response of glutamine synthetase to fasting in adult and old rats. Clin Nutr 2003;22:569-75.

91. Poirel VJ, Cailotto C, Streicher D, Pevet P, Masson-Pevet M, Gauer F. MT1 melatonin receptor mRNA tissular localization by PCR amplification. Neuroendocrinol Lett 2003;24:33-8.

92. Lewy AJ, Emens J, Sack RL, Hasler BP, Bernert RA. Zeitgeber hierarchy in humans: resetting the circadian phase positions of blind people using melatonin. Chronobiol Int 2003;20:837-52.

93. Nixon DW. Cancer, cancer cachexia, and diet: lessons from clinical research. Nutrition 1996;12: S52-6.

94. Rubin H. Cancer cachexia: Its correlations and causes. PNAS 2003;100: 5384-9.
95. Laviano A, Russo M, Freda F, Rossi-Fanelli F. Neurochemical mechanisms for cancer anorexia. Nutrition 2002;18:100-5.

96. Martignoni ME, Kunze P, Friess H. Cancer cachexia. Mol Cancer 2003; 2:1-3.

97. Argilés JM, Meijsing SH, Pallarés-Trujillo J, Guirao X, López-Soriano FJ. Cancer cachexia: a therapeutic approach. Med Res Rev 2000;21: 83-101.

98. Kotler DP. Cachexia. Ann Intern Med 2000;133:622-34.

99. Goldberg RM, Loprinzi CL. Cancer anorexia/cachexia. In: CF VonGunten, ed. Palliative care and rehabilitation of cancer patients. Boston: Kluwer Academic Publishers: 1999, 31-41.

100.Lissoni P, Paolorossi F, Tancini G., Barni S, Ardizzoia A, Brivio F, et al. Is there a role for melatonin in the treatment of neoplastic cachexia? Eur J Cancer 1996;32:1340-3.

101.Bartsch C, Bartsch H, Flúchter St-H, Meche D, Lippert TH. Diminished pineal function coincides with disturbed circadian endocrine rhythmicity in untreated primary cancer patients. Ann N Y Acad Sci 1994;719:502-25.

102.Bartsch C, Bartsch H. The modulation of pineal melatonin secretion in malignancy: results and possible mechanisms. In: SM Weeb, M PuigDomingo, M Moller, P Pévet, editors. Pineal update. Westbury: PJD Publications Limited: 1997, 369-76.

103. Martins E Jr, Fernandes LC, Bartol I, Cipolla-Neto J, Costa Rosa LFBP. The effect of melatonin chronic treatment upon macrophage and lymphocyte metabolism and function in Walker-256 tumour-bearing rats. J Neuroimmunol 1998;82:81-9.

104.Muc-Wierzgon M, Nowakowska-Zajdel E, Zubelewicz B, Wierzgon J, Kokot T, Klakla K, et al. Circadian fluctuations of melatonin, tumor necrosis factor-alpha and its soluble receptors in the circulation of patients with advanced gastrointestinal cancer. J Exp Clin Cancer Res 2003;22:171-8.

105.Ferreira ACF, Martins E Jr, Afeche SC, Cipolla-Neto J, Costa Rosa LFBP. The profile of melatonin production in tumour bearing rats. Life Science 2004. (in press)

106. Seelaender MCL, Ambrico C, Rodrigues MCPS, Boeck-Haebisch EM, Curi R. Hormonal alterations in Walker-256 tumor-bearing rats: possible role of calcium for the maintenance of cachexia. Cancer Res Ther Contr 1996;5:29-33.

107.Bacurau RF, Belmonte MA, Seelaender MC, Costa Rosa LFBP. Effect of a moderate intensity exercise training protocol on the metabolism of macrophages and lymphocytes of tumour-bearing rats. Cell Biochem Funct 2000;18:249-58.

108.Baehr EK, Eastman CI, Revelle W, Olson SH, Wolfe LF, Zee PC. Circadian phase-shifting effects of nocturnal exercise in older compared with young adults. Am J Physiol Regul Integr Comp Physiol 2003;284: R1542-50.

109.Davidson AJ, Poole AS, Yamazaki S, Menaker M. Is the food-entrainable circadian oscillator in the digestive system? Genes Brain Behav 2003;2:32-9.

110.Janik D, Nest KJ, Janiga MA. Exogenous corticosteroids and shifts of circadian rhythms in hamsters. Chronobiol Int 2001;18:203-13.

111. Krauchi K, Cajochen C, Werth E, Wirz-Justice A. Alteration of internal circadian phase relationships after morning versus evening carbohydrate-rich meals in humans. J Biol Rhythms 2002;17:364-76.

112. Skeene DJ, Swaab DF. Melatonin rhythmicity: effect of age and Alzheimer's disease. Exp Gerontol 2003;38:199-206.

113. Ohashi K, Yamamoto Y, Natelson BH. Activity rhythm degrades after strenuous exercise in chronic fatigue syndrome. Physiol Beahav 2002; 77:39-44.

114.Zajicek G. Pernicious cachexia: a different view of cancer. Anticancer Res 1999;19:4907-12. 


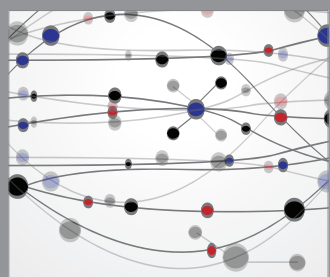

The Scientific World Journal
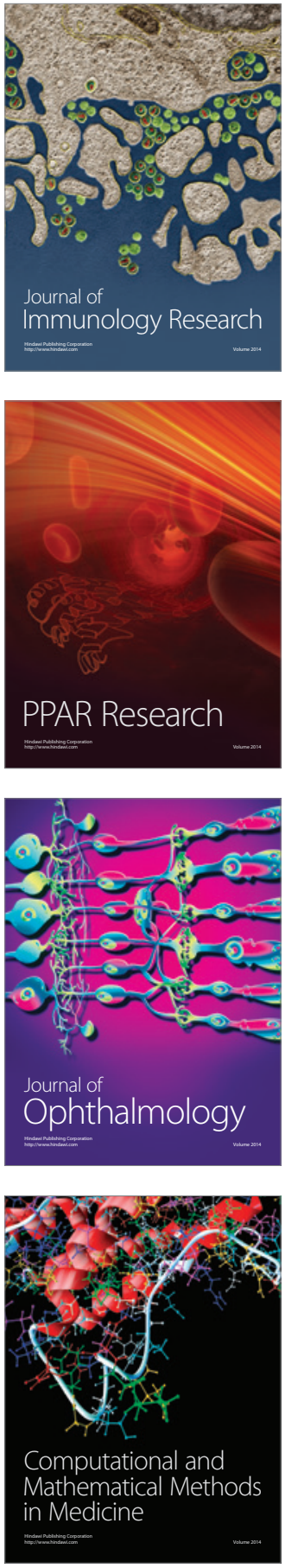

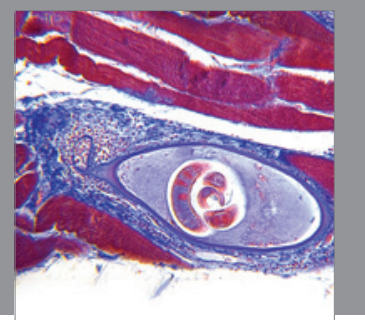

Gastroenterology

Research and Practice
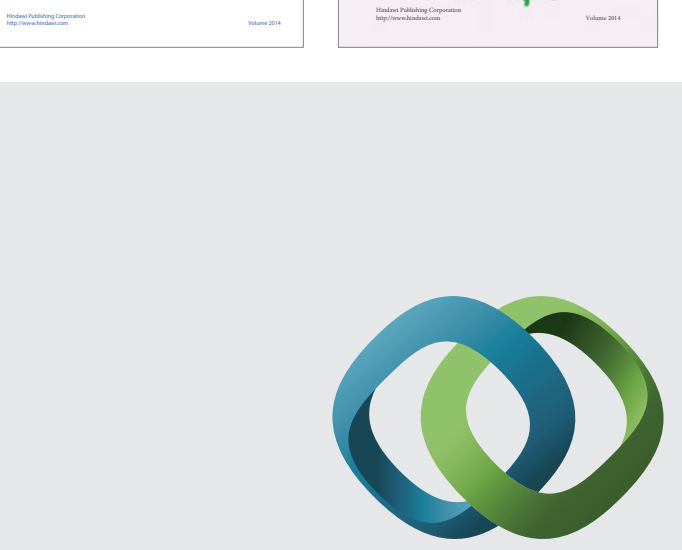

\section{Hindawi}

Submit your manuscripts at

http://www.hindawi.com
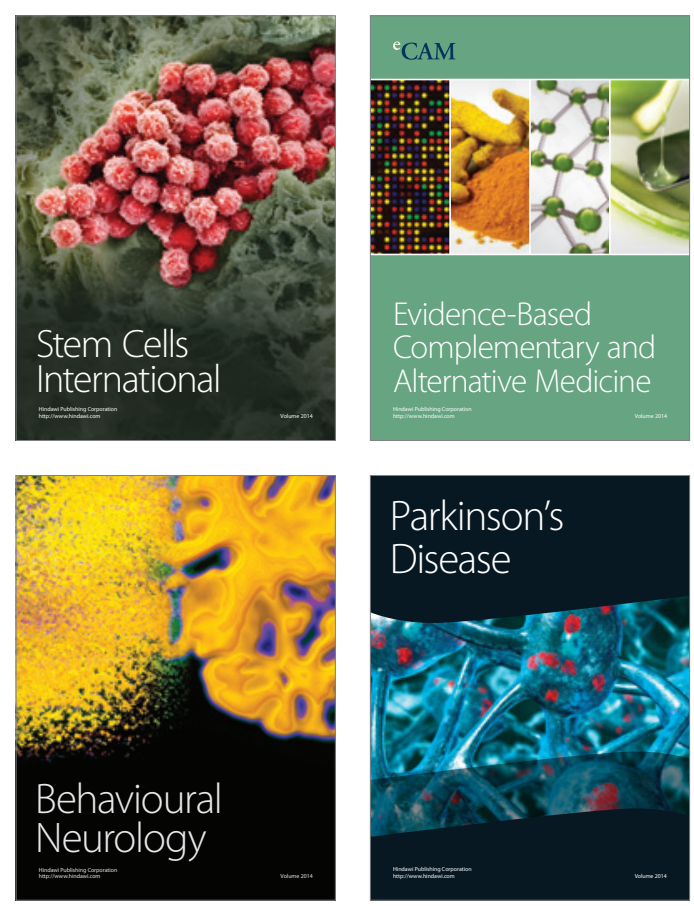

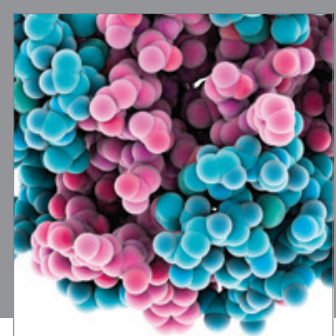

Journal of
Diabetes Research

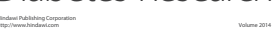

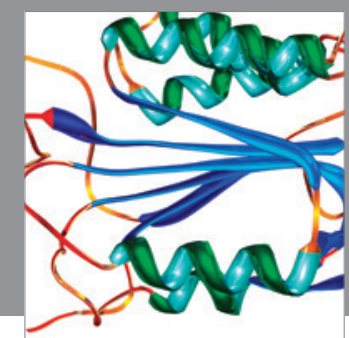

Disease Markers
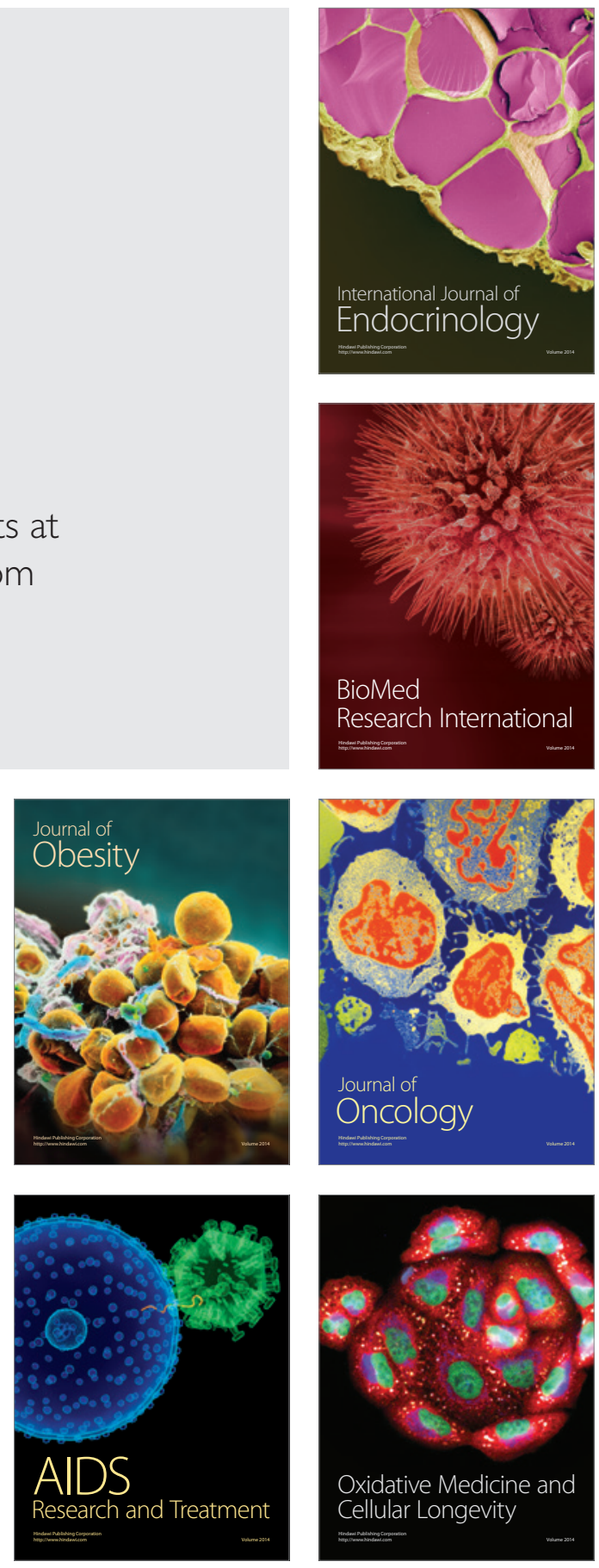